\title{
Biannual amine fluoride applications reduce caries in first permanent molars.
}

\author{
Brambilla E, Toseli A, Felloni A, Gagliani M, Malerba A, Strohmenger L. The effect of biannual applications of amine \\ fluoride solution on caries incidence in permanent first molars. Int J Paed Dent. 1997; 7: 9-14.
}

Objective To evaluate the caries preventive effect over 5 -years of biannual topical fluoride applications to permanent molars of $1 \%$ amine fluoride solution.

Design A randomised controlled trial in an Italian primary school.

Intervention After positive consent 284 children aged 6 were randomly assigned in to test and control group. All children were examined at baseline and at 6-monthly intervals. At each examination they each received fluoride toothpaste $(1-0.2 \%$ conc.). The test group had biannual applications of amine fluoride performed by personnel other than the examiners. The control group had the same procedure carried out with a placebo solution.

Results Significant differences in first molar DMFT were seen between test and control groups from the third year. Survival analysis performed on first permanent molars sound at the beginning of the study also showed a significant difference. The prevented fraction PF (Ic - It/ Ic) is calculated as $68 \%$. Using this we can calculate the numbers needed to treat at different levels of

\begin{tabular}{|c|c|c|c|}
\hline & & $\begin{array}{l}\text { Group A (Test) } \\
\text { Mean DMFT (S.D.) }\end{array}$ & $\begin{array}{l}\text { Group B (Control) } \\
\text { Mean DMFT (S.D.) }\end{array}$ \\
\hline $\begin{array}{l}\text { Start } \\
\text { End (5yrs) } \\
\text { Increment }\end{array}$ & & $\begin{array}{l}0.561 \text { (S.D. 1.069) } \\
1.143 \text { (S.D. } 1.069 \text { ) } \\
0.582\end{array}$ & $\begin{array}{l}0.226(S . D) .087) \\
2.069(S . D .1 .751) \\
1.843\end{array}$ \\
\hline \multicolumn{4}{|l|}{ Table 2} \\
\hline \multicolumn{3}{|c|}{ Caries incidence (DMFT) } & NNT (for 5 years) \\
\hline \multicolumn{2}{|r|}{$\begin{array}{l}0.25 \\
1.0 \\
1.5\end{array}$} & & $\begin{array}{l}6 \\
2 \\
1\end{array}$ \\
\hline
\end{tabular}

disease to prevent 1 DMFT using the formula 1 /incidence $\times$ preventive fraction (see table 2 ).

Conclusion Biannual high concentration amine fluoride preparation is useful and justified for community prevention programmes.

Address for reprints: Euginio Brambilla, Dipartimento di Medicina, Chirurgia Odontoiatria, Via Beldiletto 2/3-20142 Milano, Italy.

\section{Commentary}

Numerous clinical trials have been undertaken on topically applied fluorides over more than 50 years. A variety of fluoride compounds have been tested at different concentrations in a range of vehicles such as solutions, gels, pastes and varnishes. The frequency of application has varied. The studies have been conducted in different countries using different experimental designs with various diagnostic criteria. Some studies have involved young children, others used older subjects, many lasted for only a short period while others continued for several years. Comparison of the results is therefore extremely difficult.

The paper first outlines the advantages of amine fluoride over inorganic fluorides based upon in-vitro studies. It is true that the early clinical trials of amine fluoride dentifrice gave encouraging results, but these studies were not repeated by other workers. There are very few previously reported studies on the clinical effect of professionally applied amine fluoride solution and these are of short duration and have low numbers of subjects. This study was a double blind randomised clinical trial in which 248 children $(87 \%$ of those who were involved at the start) completed the 5 year programme. The results show a larger percentage reduction in caries increment compared to many other similar studies, the test group developing $68 \%$ fewer DMF teeth.

The authors conclude that the biannual application of amine fluoride solution is useful for community prevention programmes and that the cost is relatively low. The test group developed an average of 1.26 fewer DMF teeth over 5 years. Therefore it would take 4 years and $8 \mathrm{flu}$ oride applications to save one tooth. Thus over an hour was devoted to the application of the fluoride, not including the time spent preparing the subject for the treatment. Clearly the costs of such a programme are not insignificant.
At the end of the trial the control group, who were then aged 11 years, had a DMFT of 2.1. By comparison, the most recent survey in the $U K^{1}$ found the overall mean DMFT in 12 year old children to be 1.13. In the USA, where many water supplies are fluoridated, there will also be many communities with low caries rates. If carried out in an area where the caries prevalence is lower than the study, it would take even more fluoride applications to save one tooth.

It is recommended that further research should be undertaken before implementing similar programmes elsewhere. This should include a detailed investigation into the cost-effectiveness of the measure.

1 Pitts N B et al. BASCD survey report. The dental caries experience of 12 -year-old children in the United Kingdom in 1996/7. Comm Dent Hith 1998; 15: 49-54

John Beal

Consultant in Dental Public Health Leeds Health Authority, Leeds, UK 